\title{
Engineering to support wellbeing of dairy animals
}

\author{
Gerardo Caja $^{1 *}$, Andreia Castro-Costa ${ }^{1}$ and Christopher H. Knight ${ }^{2}$ \\ 'Group of Research in Ruminants (G2R), Department of Animal and Food Sciences, Universitat Autonoma de Barcelona, Bellaterra, \\ Spain \\ 2University of Copenhagen IKVH, Dyrlægevej 100, 1870 Frb C, Denmark
}

Received 17 March 2016; accepted for publication 18 April 2016

\begin{abstract}
Current trends in the global milk market and the recent abolition of milk quotas have accelerated the trend of the European dairy industry towards larger farm sizes and higher-yielding animals. Dairy cows remain in focus, but there is a growing interest in other dairy species, whose milk is often directed to traditional and protected designation of origin and gourmet dairy products. The challenge for dairy farms in general is to achieve the best possible standards of animal health and welfare, together with high lactational performance and minimal environmental impact. For larger farms, this may need to be done with a much lower ratio of husbandry staff to animals. Recent engineering advances and the decreasing cost of electronic technologies has allowed the development of 'sensing solutions' that automatically collect data, such as physiological parameters, production measures and behavioural traits. Such data can potentially help the decision making process, enabling early detection of health or wellbeing problems in individual animals and hence the application of appropriate corrective husbandry practices. This review focuses on new knowledge and emerging developments in welfare biomarkers (e.g. stress and metabolic diseases), activity-based welfare assessment (e.g. oestrus and lameness detection) and sensors of temperature and $\mathrm{pH}$ (e.g. calving alert and rumen function) and their combination and integration into 'smart' husbandry support systems that will ensure optimum wellbeing for dairy animals and thereby maximise farm profitability. Use of novel sensors combined with new technologies for information handling and communication are expected to produce dramatic changes in traditional dairy farming systems.
\end{abstract}

Keywords: Dairy technologies, biomarkers, health, welfare, husbandry, review.

\section{Background and current scenario}

As if explained by a reverse Malthusian law, the world's dairy cow milk production has increased exponentially during the last 50 years, whereas the number of dairy cows has increased linearly, with per-cow annual milk yield growing slowly from $1 \cdot 8$ to $2 \cdot 4 \mathrm{t} / \mathrm{cow}$, on average (FAOstat, 2016). In developed dairying nations the number of cows has been decreasing logarithmically, whilst annual milk yield stands at around 6.5 (EU) and 9.8 (USA) t/cow. The so-called 'white revolution' of the EU and USA dairy cow industries has been made possible by significant advances in genetics, breeding technologies and feeding resources, as reported by Capper et al. (2009). Between 1984 and 2015, EU (cow) milk production was controlled at national levels by quotas, with penalties for

\footnotetext{
*For correspondence; e-mail: gerardo.caja@uab.cat
}

overproduction and premiums for leaving farming (attractive to older farmers and small farms). This helped to maintain milk prices, but the combination of technological advance and quota caused a shift in the structure, decreasing the number of cows and farms, whilst increasing the total milk yield per cow and per farm. Milk demand is currently fully satisfied in the EU and USA, as well as in Australia and New Zealand, who process their milk surplus to produce skim milk powder for exportation. Milk powder and butter are used to address production deficits of Asia (China and Russia) and, to a minor extent, Africa.

The global scenario is changing. The preference of consumers for liquid milk rather than skim milk powder, the expensive transportation costs of liquid milk and the recent political and economic crises as well as the expansive economy of emerging countries has stimulated several investment initiatives for creating integrated, large-scale dairy farms closer to consumers. In many cases, these dairy farms are located in geographical areas not adequate 
for grazing dairy cattle (Mediterranean areas, US Central plains, Asian desserts) and submitted to severe heat or cold stress during part of the year, which requires the development of new farm facilities and highest-quality husbandry practices for high yielding dairy cows. Large-scale dairy farms use the implementation of modern engineering approaches as a way to control the whole milk production process in the farm. Extreme examples of 'super dairy' farms are: Vietnam (TH Milk project, 29000 cows with 7 milking parlours of $2 \times 30$ stalls), Saudi Arabia (Al Safi, 40000 cows with 7 milking parlours of $2 \times 50$ stalls), China (Modern Dairy Co, 40000 cows, 8 rotary milking parlours) and, most recently, the Russia-China joint development (Zhongding Dairy Farming and Severny Bur, Mudanjiang, 100000 cow places under construction).

Concurrently with these changes, skilled labour resources in many traditional EU dairy areas have become scarce and expensive because of the rural population exodus. In these cases, farm robots (e.g. automatic milking systems, feeding stations, mobile wagon feeders), based on the use of modern technologies, are often the chosen option to allow financial sustainability for family farms. In practice, the robots allow farmers to organise their working schedule more freely and to devote more time to farm management, so job replacement by robots in dairy farms has hitherto been low. Most economic indices assign considerable positive value to a high number of animals per AWU (annual working unit) which, on average, ranges between 35 and $45 \mathrm{cows} / \mathrm{AWU}$ in the specialised dairy farms of the EU (Spicka \& Smutka, 2014) and the US (Mugera \& Bitsch, 2005), respectively. Similar ratios are not economically sustainable for large-cow dairy farms (1000 cow units are unlikely to employ 25 staff) but may be needed for large buffalo farms since buffalo are more difficult to handle than cows. By comparison, the ratio for specialised small ruminant dairy farms is greater than 200 head/AWU (i.e. 5 workers/1000 ewes), as reported by Milán et al. (2011). The economic challenge facing EU dairy farmers remains acute. At the same time that the EU has relaxed quota, the world milk price has fallen, so economy of scale becomes a greater priority for dairy farmers. There is clear evidence already that those farmers who can afford to expand will do so, whilst those who cannot will leave the industry.

Dairy cows are responsible for around $83.0 \%$ of the total dairy milk production in the world (FAOstat, 2016). However, there is a growing interest in other dairy species, including buffalos, $(12.9 \%)$ goats $(2 \cdot 4 \%)$, sheep $(1 \cdot 3 \%)$ camels and others $(0 \cdot 4 \%)$. These alternative dairy species are winning market share, dairy cow milk having lost approximately $9 \%$ of the world's market in the last 50 years (FAOstat, 2016).

We use the term 'engineering' to encompass mechanical, electronic and computer engineering. A key aspect for the implementation of the new engineering technologies in the dairy industry, many of them related to TIC (technologies of information and communication), has been the dramatic reduction in size and price of electronic microprocessors, combined with a considerable increase in operating capacity. This has allowed major advances in digital electronics, enhanced data acquisition and storage, faster processing speeds, higher definition video cameras and very sensitive and cheap sensors, amongst others.

Another on-farm factor to consider is the rising cost and complexity of safety monitoring and rules for the use of chemical products (e.g. hormones and antibiotics), for reproductive technologies (e.g. hormonal treatments for fixed-time artificial insemination) or treating common dairy diseases (e.g. mastitis). This reinforces the need for cost-effective alternatives to traditional dairy husbandry practices.

\section{Dairy animal wellbeing, and the Welfare Quality ${ }^{\circledR}$ programme}

'It is health that is real wealth and not pieces of gold and silver.' This quote is from Mahatma Gandhi, the engineer of Indian independence and hence the creator of the country with the largest bovine population in the world. Of course, Gandhi had in mind human health, but the aphorism applies equally to animals. The Constitution of WHO (1946) defines good health as 'a state of complete physical, social and mental wellbeing, and not merely the absence of disease or infirmity'. In animal management we typically aim to avoid disease. To complete the picture to $\mathrm{WHO}$ ideals, we also strive for a state of (good) animal welfare, something akin to a welfare state, protecting the wellbeing of our animals (in politics, a welfare state is defined as a system 'whereby the state undertakes to protect the health and wellbeing of its citizens'). Wellbeing and welfare are in many respects interchangeable terms, but they differ in one fundamental and key way; in common use wellbeing has only one connotation (an optimum state) whereas welfare has very many definitions and is used ambiguously and without preface by those who would promote good welfare and those who decry bad welfare. Hence, we prefer to use wellbeing, whilst recognising the usefulness of Duncan and Fraser's definition of welfare as comprising 'the state of the animal's body and mind, and the extent to which its nature (genetic traits manifest in breed and temperament) is satisfied' (Duncan \& Fraser, 1997). Although concerns for animal wellbeing have existed since Neolithic times, the 'human-animal bond' being a clue of the domestication process, there is widespread agreement that humans seriously threatened animal wellbeing by the intensification of livestock production systems. Animal protein demand is expected to increase rapidly in the future as a response to human population growth and, consequently, livestock production will grow and intensify more. Animal wellbeing becomes a top priority for EU citizens and in the current livestock policy of the European Commission, as included in its aims for the Horizon 2020 programme. This is also reflected in funding for two FP7 projects, EU PLF (Precision Livestock Farming: EU-PLF, 2016), which includes dairy cattle, and ProHealth (FP7ProHealth, 2016) which is focused on pigs and poultry. 
Dairy animal husbandry refers to the relationship of dairy farmers with their animals and the duty they have to ensure that their animals are given the very best of care whilst trying to optimise their production cycles and lactational performances in a cost-effective way. In the authors' minds, wellbeing and good husbandry are synonymous, although it is noteworthy that most definitions of animal husbandry pay scant attention to wellbeing.

Whilst wellbeing is important in all production animals, dairy animals have some unique needs derived from their specific characteristics, but also provide some special opportunities for management. For instance:

- Management attention must be geared towards females which have longer expected productive life than most other livestock species

- High-yielding dairy animals have increased susceptibility to heat stress, metabolic problems (ketosis, acidosis, hypocalcaemia), infectious diseases (mastitis, metritis) and multi-factorial diseases (lameness) which are mainly concentrated at specific points in the lactation cycle (peri-partum, early lactation)

- The farmer's needs for high fertility (early return to oestrous after parturition) and the cow's needs to avoid additional energetic expenditure may be in conflict

- Technological and biotechnological innovation in automated health diagnostics are more advanced in dairy than in other animal production systems, a number of sensor devices being commercially available at affordable prices

- Regular milking (twice- to thrice-daily) provides opportunities for diagnostic observation

The reality is that productive lifespan averages 2-3 and rarely exceeds 3-4 lactations, the culling rate ranging from 21 to $36 \%$ in dairy cows, being greater in USA than in EU and being dramatically affected by milk price (Mohd-Nor et al. 2014). The main involuntary culling reasons are reproductive failures and udder health issues, each comprising between a quarter and a third of total culling (Chiumia et al. 2013). Culling values are greater in larger and higher-yielding dairy cow farms (Hadley et al. 2006) and under low-forage diets regardless of the cow's parity (Chiumia et al. 2013). Dairy buffaloes, sheep and goat have similar culling patterns but life span is usually longer in buffalo and sheep than in goats). There is considerable interaction between different characteristics. Dairy cows with subclinical ketosis are $20-50 \%$ less likely to become pregnant at first Al than normal cows (Walsh et al. 2007) and show greater lethargy and lying times (Itle et al. 2015). Similar effects have been reported in dairy goats (Zobel et al. 2015). There is also considerable variation between animals in what is 'normal'. Take the example of oestrous duration, which varies between individuals, between breeds, according to production level and in response to nutrition and environmental factors. Oestrous is an example of a natural behaviour that makes management more difficult: most cows show standing oestrous behaviour from sunset to dawn, leading to the common practice of the 'a.m.-p.m. rule' (cows detected standing in the morning will be inseminated in the afternoon, and those detected in the evening will be inseminated the next morning). Values of fertility are low, the cumulative probability of conception between 20 and 145 DIM ranging from 0.5 to $46 \%$ in dairy cows (Madouasse et al. 2010) evidencing a large room for improvement. Technologies are not circadian! Furthermore, once one has invested in the technology the add-on costs of frequent use are minimal, meaning that repeated measurements can be made in each animal (at each milking, for instance) so that she can be tracked across time.

Welfare assessment of dairy animals is a hard and multidisciplinary task, one that must take into account a number of objective measures but also a great many subjective ones. There is general agreement that animal welfare is assured when the 5 main freedom principles stated in 1979 by the UK's Farm Animal Welfare Council (FAWC) are fulfilled. These freedoms (freedom from hunger and thirst, from discomfiture, from pain, injury and disease, from fear and distress and freedom to express most normal behaviours) are internationally recognised, but they are ideal states rather than standards for acceptable welfare. Moreover, as pointed out by FAWC 'there is no gold standard to measure good animal welfare' (FAWC, 2014), considering that objective measures can be defined or recorded in some cases (e.g. lameness or injuries), but others are currently very difficult to assess (e.g. sadness, happiness, fear). Welfare Quality ${ }^{\circledR}$ was an EU FP6 research programme that developed semi-objective protocols for assessing farm animal welfare. For cattle (dairy, beef and veal calf) farms they identified 4 welfare principles (good feeding, good housing, good health and appropriate behaviour), 12 welfare criteria and 53 management practices (Forkman \& Keeling, 2009). The definition of good health was absence of disease, injuries and pain, with physical, social and mental wellbeing assessed through four measures of appropriate behaviour. Two important principles of the Welfare Quality ${ }^{\circledR}$ approach should be recognised:

- the programme was fork to farm, i.e. lead by consumer expectations

- the protocols that emerged use animal based measures but are farm level assessments

The Welfare Quality ${ }^{\circledR}$ protocol has been adopted and is being used, farms being categorised as Excellent, Enhanced, Acceptable and Unclassified (unacceptable). The protocol is not without its critics; it is time consuming and costly and a small number of individual measures have a major impact on the classification and may thus become foci of effort to improve classification rather than actual animal wellbeing (De Vries et al. 2013). Our major concern is very simple: the approach does not provide the farmer with a toolbox for ongoing assessment of the 
wellbeing of his cows, nor was it ever meant to do so. The questions that emerge are, does the farmer need such a thing, and can we provide it, either now or in the foreseeable future?

\section{The DairyCare concept; individualised wellbeing through integrated action}

Can technology provide data that is (a) animalcentric (relating to each individual cow) and (b) useful to the farmer? One individual brand of oestrous detection technology (an accelerometer placed in an ear tag) is reported to have sold $1.7 \mathrm{M}$ items worldwide (Michaelis et al. 2014), and we can identify at least 11 other commercially available accelerometer technologies intended for oestrous detection (Table 1). The extent to which these technologies have been scientifically validated varies, but the main conclusion is quite clear: dairy farmers will pay for and use technologies that provide what is, to them, a straightforward answer to a straightforward question (should I inseminate cow $\mathrm{x}$ ?) when they believe it will have positive economic impact. It is in that context that we should consider whether technology can assist dairy animal wellbeing.

Animal wellbeing is multifactorial, and one of the premises underlying the DairyCare project is that achieving the best solutions will require inputs from animal scientists, ethologists, veterinarians and agricultural engineers, working in partnership with small and medium sized enterprises (SME) and dairy equipment companies. The route to market identifies that this multidisciplinary cooperation will assist the development of technologies that are then integrated into best practice blueprints, which are then channelled through dairy consultancies to achieve better dairy animal welfare on farms that are more profitable as a result. DairyCare (COST Action FA1308) is a 4 year (March 2014 to March 2018) researcher network focused on dairy animal health and welfare which has as its main objective the improvement of dairy animal wellbeing through scientific and technological advance within the EU dairy industry (DairyCare, 2016). By enabling better wellbeing, DairyCare also aims to create positive societal impact from added value throughout the dairy foods chain. Good wellbeing links directly to high quality and high productivity, hence longer term benefits will result from a positive contribution to the challenges posed by global food security. By involving SMEs in the development of new husbandry-support technologies that will have application around the world, DairyCare will contribute to European economic growth.

To achieve the most productive outcomes, DairyCare is organised into outcome-oriented Working Groups (WG) that are responsible for the development of:

- Biomarker-based welfare technologies (WG1),

- Activity-based monitoring welfare technologies (WG2), and

- Systems-level welfare technologies (WG3).
Effective strategies for improving dairy animal wellbeing require collaboration across a broad range of specialist and expert skills. Most of the necessary expertises already exist within Europe, but are dispersed across different countries in ways that are influenced by regional differences in dairy farming strategies and hence research emphasis. The first immediate benefit of DairyCare is to bring together these disparate skillsets. Technological advance will be accelerated by knowledge exchange and synergism between disciplines, targeted towards a series of specific and achievable future outcomes. Animal scientists have knowledge of welfare physiology, veterinarians have knowledge of animal health and disease, biotechnologists have knowledge of proteomics and metabolomics. Together, these skills will enable the future development of novel wellbeing related biomarkers, the first outcome set (WG1). Ethologists have knowledge of animal behaviour and the activities that are indicative of good or bad welfare, whilst electronic engineers have expertise in the automatic capture of visual, auditory or locomotion data that relates to these activities. The combination of these skills enable the future development of activity-based wellbeing measures, the second outcome set (WG2). To ensure application of these novel wellbeing technologies in practice, DairyCare includes agricultural engineers with knowledge of milking and management systems and computer scientists with knowledge of the design of algorithms for data extraction, analysis and interpretation. Through the combination of these skills, the biomarker and activity data will be used to construct future decision support systems that will assist farmers to optimise the wellbeing of their dairy animals, the third outcome (WG3). DairyCare supports a range of cross-disciplinary networking activities and uses a number of tools to achieve its objectives such as: open conferences for scientific debate around relevant topics, WG meetings for more focused debate in smaller groups about specific topics, Research Training Workshops (RTW) for providing training in relevant techniques for younger scientists, and Best Practice Workshops (BPW) to disseminate best practices to end-users. The DairyCare integrative concept is shown in Fig. 1, and Fig. 2 gives an overview of some of the specific topic-based activities that have already taken place or are scheduled. Proceedings from the three scientific conferences are published and available online (DairyCare, 2016):

- Health and welfare of dairy animals (held in Copenhagen in 2014)

- Lameness/Reproduction interface (held in Córdoba in 2015)

- Feeding behaviour as an indicator of health and welfare (held in Zadar in 2015)

\section{Available technologies}

Current management capabilities in the dairy sector include the ability to identify, traffic and milk individual animals, 
Table 1. Currently available engineered devices for monitoring the performances and wellbeing of dairy cows

$\begin{array}{llll}\text { Objective } & \text { Manufacturer (address } \dagger \text { ) } & \text { Type \& features } & \text { Technology used } \\ \begin{array}{c}\text { Milk } \\ \text { composition }\end{array} & \begin{array}{c}\text { AfiLab (Afimilk, Kibbutz } \\ \text { Afikim, IL) }\end{array} & \text { In-line milk composition } & \text { Near-IR }+ \\ \begin{array}{c}\text { Somatic cell } \\ \text { count (SCC) }\end{array} & \text { OCC, DeLaval (Tumba, } & \text { Milk SCC by udder } & \text { Analysis of cell ADN by } \\ & \text { quarter } & \text { u.v. fluorescence }\end{array}$

Body condition scoring (BCS)

Metabolic
biomarkers
Activity behav-
iour (oestrous,
feeding and
health signs
detection)

Herd navigator, Lattec I/S Biomarkers in milk

(Hillerod, DK)

CowManager, SensOr, Ear: activity, feeding,

Agis Automatisering

(Harmelen, NL)

Cow Alert, IceRobotics

(Edinburgh, Scotland, UK)

CowScout, GEA

(Düsseldorf, DE)

Qwes (Lely, NL)

Activity meter, DeLaval

(Tumba, SW)

Silent Herdsman Afimilk

(Kibbutz Afikim, IL)

MooMonitor, DairyMaster

(Tralee, IE)

HeatPhone, Medria

(Chateaubourg, FR)

Gyuho SaaS Fujitsu

(Fukuoka, JP)

HeatWath II, CowChips

(Manalapan, NJ, US)

Heatime, EFS (Westmeath,

IE)

HeatSeeker, BouMatic

(Madison, WI, USA)

RumiWatch, Itin+Hoch

(Liestal, $\mathrm{CH}$ )

Lameness

StepMetrix, BouMatic

(Madison, WI, USA)

Gaitwise, ILVO (Merelbeke, Mat for gait consistency $\mathrm{BE})$

$\begin{array}{cc}\text { Mating alert } & \text { Celotor (Cali, CO) } \\ \text { Calving alert } & \text { Vel'Phone, Medria } \\ & \text { (Châteaubourg, FR) } \\ & \text { iVET birth-monitoring } \\ & \text { (Papenburg, DE) } \\ & \text { Moocall (Dublin, IE) }\end{array}$

Lower back image (loin, 3D imaging rump, hook, tailhead fatness)

health

Leg: activity, oestrous,

health

Neck or leg: activity, eating time, oestrous

Neck: activity, oestrous rumination,

Neck: activity, oestrous, health

Neck or leg: activity, oestrous, rumination

Neck: activity, oestrous health

Neck: oestrous, health

Leg: activity, oestrous, health

Tailhead: oestrous

Neck: activity, oestrous, health

Leg: activity, intake,

Nose and leg: activity, intake, drinking, rumination, lameness

Platform for gait consistency

Mat for gait consistency Time and force sensor

Harness reader and tail inject

Vaginal temperature

Vaginal temperature

Tail ring oestrous, lameness
Fourier transform mid-IR

RF§, 3-axial accelerometer

RF, 3-axial accelerometer

RF, 3-axial accelerometer

RF, 3-axial accelerometer

RF, 3-axial accelerometer

RF, 3-axial accelerometer

RF, 3-axial accelerometer, SMS

RF, 3-axial accelerometer

RF, 3-axial accelerometer

RF, pressure

RF, 3-axial accelerometer

RF, 3-axial accelerometer

RF and USBtt, 3-axial accelerometer, thermistor, pressure

Time and force sensor

RF, SMS

Thermistor, SMS

Thermistor, SMS

Accelerometer, SMS
Reference link

http://www.afimilk.com/products/ milking-parlor-automation/integrated-milking-point-analysiscontrol

http://www.delaval.com/en/-/ Product-Information1/Milking/ Products/Stallwork/VMS-station/ DeLaval-online-cell-counterOCC/

http://www.delaval.com/en/-/ Product-Information1/ Management/Systems/DeLavalbody-condition-scoring-BCS/ http://www.herdnavigator.com/ pages/id1.html http://www.cowmanager.com/enus/

http://www.icerobotics.com/ products/

http://www.gea.com/global/en/ products/activity-detectioncowscout.jsp

http://www.lely.com/en/milking/ detection-system/qwes http://www.delaval.com/en/-/ Product-Information1/ Management/Systems/Activitymeter-system/

http://www.afimilk.com/products/ cow-monitoring

http://www.dairymaster.com/ heat-detection/

http://www.medria.fr/en_GB/ produits/heatphone.html

http://www.fujitsu.com/jp/group/ kyushu/en/solutions/industry/ agriculture/gyuho/ http://www.cowchips.net/index. html

http://www.efsltd.ie/

http://www.boumatic.com/us-en/ products/heatseeker1

http://www.rumiwatch.ch/index. html

http://www.boumatic.com/eu-en/ products/view/stepmetrix http://www.dairycareaction.org/ uploads/2/4/2/6/24266896/4. 2_van_nuffel.pdf http://www.celotor.com/celotor/ partes-y-operacion http://www.medria.fr/en_GB/ produits/vel-phone.html http://www.birth-monitoring.com/ home/birth-monitoring/ http://www.moocall.com/ 
Table 1. (Cont.)

\begin{tabular}{|c|c|c|}
\hline Objective & Manufacturer (address $\uparrow$ ) & Type \& features \\
\hline \multirow[t]{4}{*}{ Rumen function } & eCow Devon (Exeter, UK) & $\begin{array}{l}\text { Rumen bolus: } \mathrm{pH} \text {, tem- } \\
\text { perature, drinking }\end{array}$ \\
\hline & $\begin{array}{l}\text { San'Phone, Medria } \\
\text { (Chateaubourg, FR) }\end{array}$ & $\begin{array}{l}\text { Rumen bolus: tempera- } \\
\text { ture, drinking }\end{array}$ \\
\hline & $\begin{array}{l}\text { Well Cow (Roslin, } \\
\text { Midlothian, UK) }\end{array}$ & $\begin{array}{l}\text { Rumen bolus: } \mathrm{pH} \text {, } \\
\text { temperature }\end{array}$ \\
\hline & $\begin{array}{l}\text { SmaXtec pH \& Temp } \\
\text { Sensor, SmaXtec Animal } \\
\text { Care (Graz, AT) }\end{array}$ & $\begin{array}{l}\text { Rumen bolus: } \mathrm{pH} \text {, tem- } \\
\text { perature, drinking }\end{array}$ \\
\hline $\begin{array}{l}\text { Integrated } \\
\text { functions }\end{array}$ & $\begin{array}{c}\text { SmaXtec Sensor, SmaXtec } \\
\text { Animal Care (Graz, AT) }\end{array}$ & $\begin{array}{l}\text { Rumen bolus: activity, } \\
\text { temperature, drinking, } \\
\text { oestrous }\end{array}$ \\
\hline \multirow[t]{3}{*}{$\begin{array}{l}\text { Position } \\
\text { location }\end{array}$} & $\begin{array}{l}\text { WildCell, Lotek (Ontario, } \\
\text { CA) }\end{array}$ & Neck \\
\hline & CattleWatch (Rehovot, IL) & Neck, ear \\
\hline & $\begin{array}{l}\text { Ser. } 500 \text { Cluster } \\
\text { Geolocation System, } \\
\text { Omnisense (Cambridge, } \\
\text { UK) }\end{array}$ & Neck \\
\hline
\end{tabular}

\begin{tabular}{|c|c|}
\hline Technology used & Reference link \\
\hline $\begin{array}{l}\mathrm{RF}, \mathrm{pH} \text { electrode, } \\
\text { thermistor }\end{array}$ & http://www.ecow.co.uk/ \\
\hline Thermistor, SMS & $\begin{array}{l}\text { http://www.medria.fr/en_GB/ } \\
\text { produits/san-phone.html }\end{array}$ \\
\hline $\begin{array}{l}\mathrm{RF}, \mathrm{pH} \text { electrode, } \\
\text { thermistor }\end{array}$ & http://www.wellcow.co.uk/bolus/ \\
\hline $\begin{array}{l}\mathrm{RF}, \mathrm{pH} \text { electrode, } \\
\text { thermistor }\end{array}$ & $\begin{array}{l}\text { http://www.smaxtec-animalcare. } \\
\text { com/en/products-services/ } \\
\text { smaxtec-ph-temp-sensor/ }\end{array}$ \\
\hline $\begin{array}{l}\text { 3-axial accelerometer, } \\
\text { thermistor }\end{array}$ & $\begin{array}{l}\text { http://www.smaxtec-animalcare. } \\
\text { com/en/products-services/ } \\
\text { smaxtec-sensor/ }\end{array}$ \\
\hline $\begin{array}{l}\text { GPS, RF, temperature } \\
\text { sensor, 2-axial } \\
\text { accelerometer }\end{array}$ & $\begin{array}{l}\text { http://www.lotek.com/wildcell. } \\
\text { htm }\end{array}$ \\
\hline GPS, RF & http://www.cattle-watch.com/ \\
\hline $\begin{array}{l}\text { RF, mesh network indoors } \\
(200-400 \mathrm{~m})\end{array}$ & $\begin{array}{l}\text { http://www.omnisense.co.uk/ } \\
\text { agriculture.html }\end{array}$ \\
\hline
\end{tabular}

$\dagger$ Officially assigned country codes: ISO 3166-1 alpha-2 codes Infrared spectroscopy §Radio frequency (ultrahigh frequency) ฯ Mobil-to-mobil short message service †Universal serial bus connection

feed concentrates and total mixed rations fully automatically, and to obtain diagnostic data informing about several health and performance related criteria. A chosen set of the most important commercially available technologies currently in use for dairy cows is shown in Table 1 and Fig. 3.

\section{Identification was first}

An early evidence of the development of new technologies in the agricultural sector is the patent of Hanton \& Leach (1974) on the first radiofrequency (RF) identification (ID) system of cattle using a glass encapsulated rumen bolus powered by a battery. The bolus was administered orally, retained in the reticulo-rumen, and its internal RF circuitry responded with a coded signal when interrogated by a stationary unit working at $75 \mathrm{MHz}$ and placed at 3-5 m of distance. The current technological state-of-the-art in the livestock sector is centred on the individual animal, and most RFID transponders used today are inspired by Hanton \& Leach's original idea. RFID is heavily used in the dairy sector, and together with the fact that each lactating animal will regularly come to one specific point to be milked provides the basis of the individualistic management approach.

High performance RFID devices, allowing non-contact and fast dynamic reading, are a key priority for all engineered developments to be used under on-farm conditions. Current RFID of dairy cows is still based on large high- frequency transponders (i.e. neck collars) although miniaturised low-frequency devices of different ISO (International Organisation for Standardisation) technologies are cheaper and readily available (ear tags, injectable devices or rumen boluses). Interestingly, whilst RFID technology for cattle is an option for farmers in most EU countries (only Denmark has approved the generalised use of RFID in cattle), the current EU regulations compulsorily require the use of RFID in all small ruminants (breeding stock older than 6 months located in countries with more than 600000 head) as the only way to trace and to build up credible animal inventories. Moving to compulsory RFID for cattle could help to accelerate the introduction and implementation of associated and new technologies (Caja et al. 2014). It should be pointed out that the RF needs are markedly different if intended for animal ID (low-frequency, $134.2 \mathrm{kHz}$ ) or for big data collection and transmission (high frequency, $13.56 \mathrm{MHz}$; very-high and ultra-high frequency, 400-900 $\mathrm{MHz}$ ), the reading of both RF variants being specific and the transceivers not intercompatible. Moreover, ID transponders are usually passive (without battery) whereas data collectors and transmitters are active (with battery or their own source of energy). An animal with a missing, lost or non-readable transponder will be 'invisible' to the technology. As a result, when a sequential reading procedure is used (such as a line or rotary milking parlour, dynamic weighing scales) the ID of all animals behind the 'not read' will be mis-assigned, which must be avoided. 


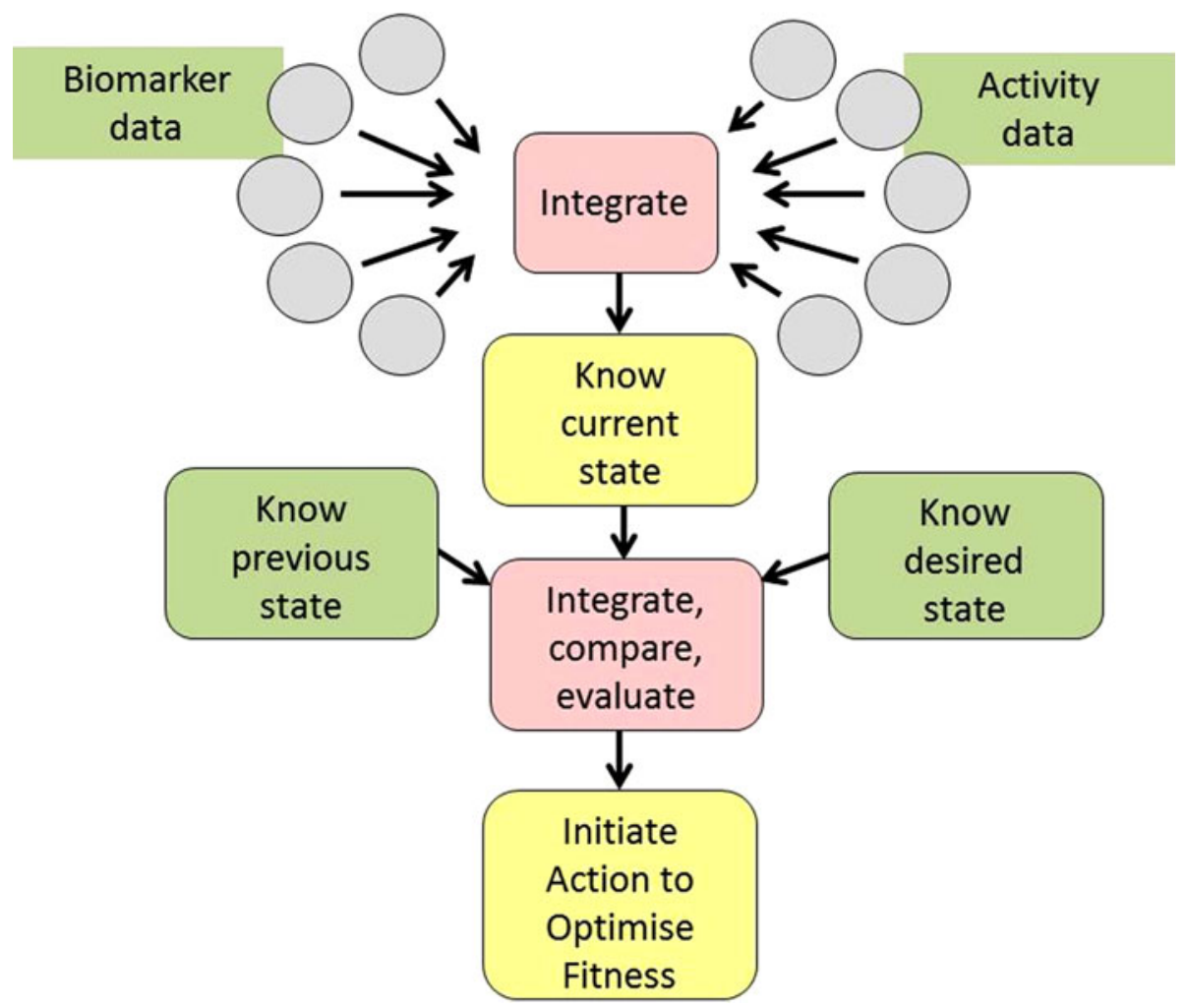

Fig. 1. The DairyCare concept. Data collected from biomarker sensors and from activity sensors are integrated to create an understanding of the cow's current status. This is compared with her own previous state and the state that is desired for a healthy cow of the same physiological stage. If the cow's status falls outside the desired range, she is flagged for action.

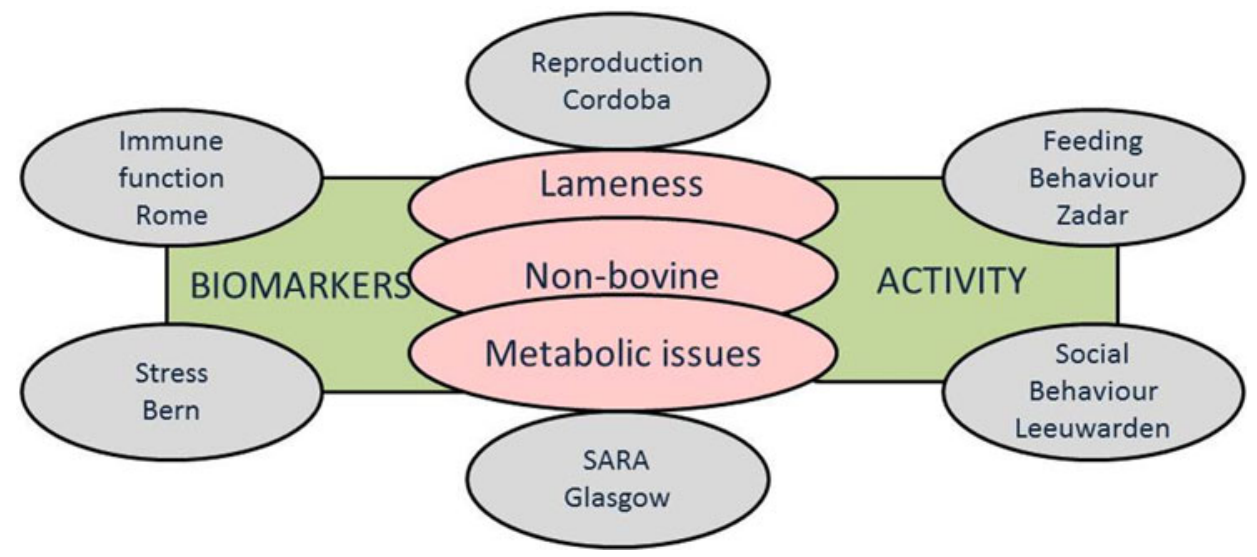

Fig. 2. Topics that have been covered in the COST ActionFA1308 DairyCare Programme to date (to summer 2016). More information can be found online at http://www.dairycareaction.org.

\section{Using TICs for dairy wellbeing}

The implementation of $\mathrm{TIC}$ and especially the recent concepts of SNO (smart networked objects) and loT (internet of things), opened a new era of communication in which things, not only humans or animals, are the main users of local communication wireless networks and internet. This is communication anytime, anywhere, by anyone and anything, providing 'things' with an individual identity and virtual 'personality' which operates in smart spaces using intelligent interfaces to create new values (AIC, 2010). In practice the creation of so called M2M (machine to machine) real-time or near-real-time connectivity is also necessary. All 'things' need to be embedded with microelectronics, 


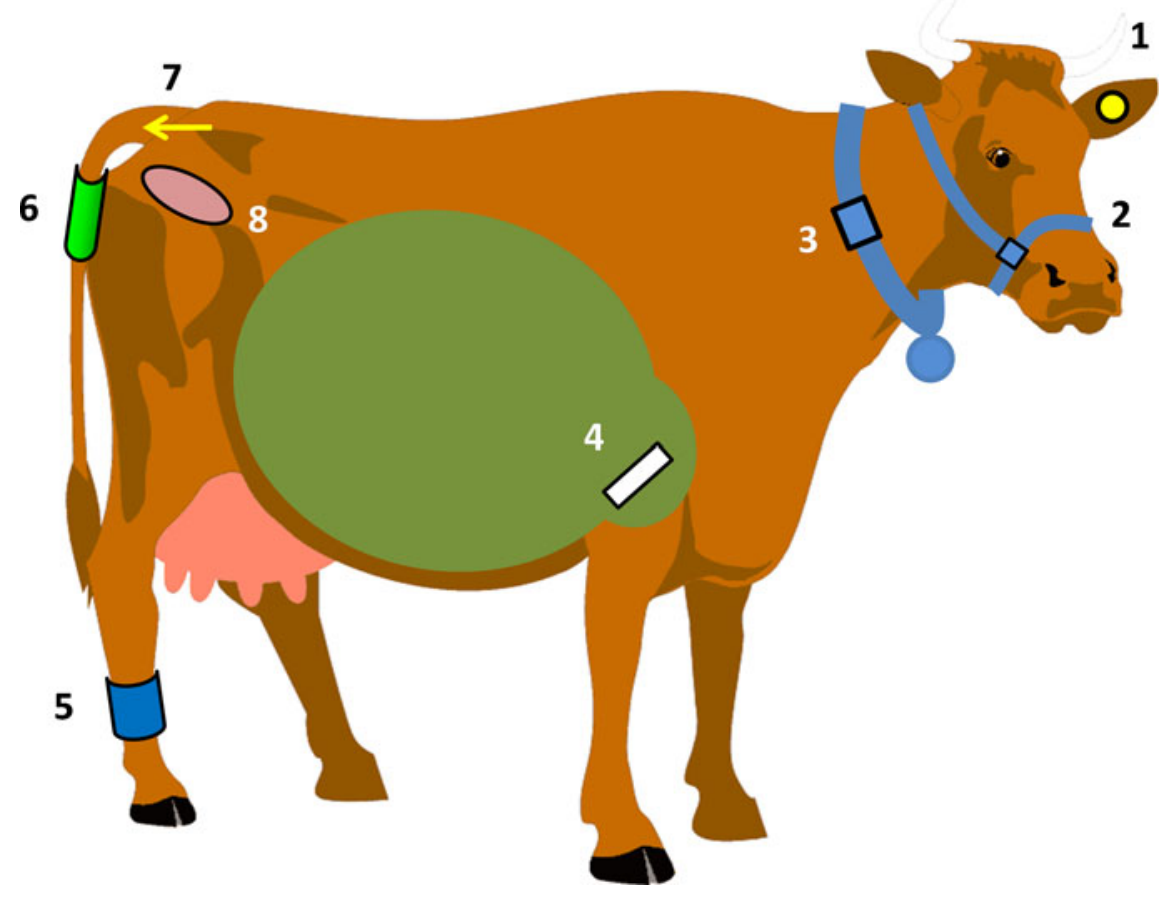

Fig. 3. Location of engineered devices for in situ data collection in a cow: (1) ear tag, (2) halter, (3) neck collar with counterweight, (4) reticulo-rumen bolus (in reticulum), (5) rear leg pedometer, (6) upper tail ring, (7) tailhead inject, and (8) vaginal bolus.

sensors and software, that let them connect, exchange data with a central operator and be able to communicate, either directly with a network, internet or with internet-connected devices. In fact, 'things' in the loT and 'machines' in M2M, are physical entities whose identity, state (or the state of their surroundings) are capable of being relayed to an internetconnected TIC infrastructure.

The implementation of TICs in the livestock industry, and lately the use of SNO and loT, lead to the new concept of PLF (precision livestock farming) which aims to automatically monitor individual animals for optimising their production process. According to Berckmans (2008), PLF consists of measuring variables, modelling the data to select information, and then using these models in real-time for monitoring and controlling the animals. Originally intended for application in agronomy, we consider that the use of the 'precision' term in livestock is not fully expressing the needs of FAWC's freedoms required in animals and PLF should be used jointly with the concept of 'good practice'. The main variables that might be monitored by PLF are the use of key livestock resources (feed, water, land surface), performances (milk yield, weight), health (for instance coughing, body temperature, lameness), behaviour (activity, rumination, fighting) and environment (temperature, humidity, air speed, toxic gases). PLF is a technological response to the loss of contact between husbandry staff and animals, as a result of larger more automated farms, providing accurate information to reduce dependency on human labour and informing decision making. PLF has many possibilities of use with regard to wellbeing in the dairy industry, either for intensive large-dairy farms or extensive (Bocquier et al. 2014). Many TIC companies stand to benefit from this new world of opportunities, including mobile network operators and fixed broadband providers, system integrators, cloud service providers, mobile App developers, sensor and wireless infrastructure vendors, and purveyors of big data infrastructure and analysis.

Another concept introduced by the TIC industry is that of 'wearable' devices such as smart watches or smartglasses (in humans) and, in the SNO and loT context, they are devices connected to RF networks or internet, respectively. As we have seen, cows have their own wearable devices (Fig. 3), which complement the RFID devices and are intended to monitor what the cow is doing and provide early detection of health or behavioural problems. With this purpose, most wearable devices are equipped with sensors. Rutten et al. (2013) categorised the available sensors to support health management on cow dairy farms and schematised the framework that describes the steps followed from a sensor to a decision.

\section{Non-wearable devices}

Automated milking systems (AMS) in dairy cows are a good example of how non-wearable TICs can be integrated with automation (robotic arms) to help dairy husbandry staff by reducing routine workload and freeing-up time for management tasks, which are simultaneously assisted by automatic and real-time data collection (the latter can happen in conventional milking parlours as well). Once the RFID has 
provided the identity, milk flowmeters, milk conductimeters, infrared or laser assisted video cameras collect data that are then integrated in computers by specific 'smart' software using complex algorithms previously validated with assumed gold standards, usually derived from observational data. Data are abundant, so let us examine the outcomes (Table 1).

Technologies are available for recording of body weight and of food intake using automated electronic scales which were developed in the EU and involve SMEs and larger enterprises from EU and other COST countries (including Switzerland and Israel). Imaging technologies are also available, such as 3D imaging for body condition scoring ('DeLaval BCS'; Krukowski, 2009) and infrared thermography for exploring udder health, although this last is currently questioned (Castro-Costa et al. 2014). Force sensors are being used in gait consistency analysis for lameness detection ('StepMetrix' and 'Gaitwise').

Milk composition can provide information about nutrition, metabolic state and health through changes in major (Sutton \& Morant, 1989) and minor milk components (Larsen et al. 2016). Milk sampling has the major advantage of being non-invasive and automatable, and the combination of routine sampling and the generalised use of MIR (mid-infrared) spectrometry in dairy herd improvement programs focused on 'simple' protein, fat and lactose composition also now allows the simultaneous detection of more informative biomarkers such as ketone bodies and individual fatty acids (De Marchi et al. 2014). An application example is the use of fatty acids profile for predicting methane emission (van Gastelen \& Dijkstra, 2016).

A number of integrated in-line/real time milk analysis technologies are available. Afimilk's 'AfiLlab' system (Leitner et al. 2012) is able to measure the major milk components (i.e. fat, protein and lactose) and milk coagulation properties by near-infrared analysis (NIR), and can be combined with the 'Online Cell Counter' for somatic cell count (SCC) based on the analysis of cell's ADN by u.v. fluorescence (Albrechtsen et al. 2011). Lattec's 'Herd Navigator' focuses on milk biomarkers for the detection of oestrous (progesterone analysis), subclinical and acute mastitis (lactate dehydrogenase analysis) and ketosis ( $\beta$-hydroxybutyrate analysis, BHB). The Herd Navigator system automatically selects the cow to sample, at which milking session it should be monitored and which variables should be measured. New robotic collection and analysis of biological samples (e.g. milk, saliva, sweat and hair), including the use of metabolomics and proteomics, are under development to obtain data of metabolic disorders and wellbeingrelated biomarkers which could be applied not only in cows but also in sheep, goats and others.

\section{Wearable devices}

Activity sensors (Table 1 and Fig. 3) are wearable devices that are now used very commonly in dairy herds. Most reproductive management technologies (e.g. oestrous, mating, calving) are based on activity-recording of one sort or another using tri-axial accelerometers ('SensOor', 'Cow Alert', 'CowScout', 'Qwes', 'Activity meter', 'Silent Herdsman', 'Gyuho SaaS', 'HeatWath II', 'Heatime', 'HeatSeeker' and 'RumiWatch'). They are offered to wear as an ear tag (Bikker et al. 2014), nose halter, neck collar or leg (preferably rear) pedometer. Some accelerometers also offer information on feeding behaviour (e.g. eating, ruminating, drinking). Special case is the 'MooMonitor' which is using pressure sensors for detecting the standing behaviour of dairy cows during oestrous.

Simpler devices for heat and mating activity detection use RFID transceivers attached to a harness for bulls or androgenised cows ('Celotor'). Cows are identified with an injectable transponder in the tailhead which is read by the transceiver at mounting.

Calving detection is monitored by changes in tail position with devices attached to the tailhead containing accelerometers ('Moocall') or by the dramatic change of temperature of a vaginal device using thermistors when it is expelled during labour ('Vel'Phone' and 'iVET').

Reticulo-rumen boluses ('eCow', 'WellCow', 'smaXtec $\mathrm{pH}$ ') assess rumen function by specific sensors (e.g. temperature, $\mathrm{pH}$, pressure) which might be related to rumen $\mathrm{pH}$ for SARA (subacute rumen acidosis) detection and with feeding and drinking behaviour. Additionally, data provided by an integrated tri-axial accelerometer offers information on reproductive activity, feeding and locomotion for integrated farm management decisions, including lameness detection ('smaXtec Sensor': smaXtec, 2016). A simpler case is the 'San'Phone' only equipped with thermistors informing about rumen temperature and drinking bouts.

Additionally, position location is offered by GPS devices, in some cases associated with 2 or 3 axial-accelerometers and thermistors ('WildCell', 'CattleWatch' and 'Ser. 500 Cluster Geolocation System'), usually used in extensive livestock or wild animals under on-field conditions.

All of these technologies are capable of identifying livestock requiring attention or 'at risk' and communicating with dairy farm staff at any time using M2M communication by App and SMS telephone messages. We have identified technologies that are commercially available, recognising at the same time that others will exist at various stages of experimental development. It would not be appropriate to comment on the usefulness or otherwise of the individual commercial technologies, since the claims made for accuracy, precision, false positives and negatives are in most cases those of the manufacturer and have not been tested independently. We do, however, offer the following observations:

- Although manufacturers often claim to offer 'complete solutions', no one system individually offers everything that could be achieved by using a full combination of all systems operating together

- Almost without exception, the different technologies operate 'stand alone', and will not communicate with each other 


\section{The future}

The term 'psychedelic cowbell road' has nothing to do with cows, it is a name coined to describe the dashboard display of a popular make of electric car when driven in autopilot mode. If driverless cars are to work (and many manufacturers are determined that they will) technology needs to provide two things:

- a continuous and detailed 360 degree assessment of the car's environment that can detect every object and determine what that object is likely to do in the foreseeable future

- algorithms that will ensure that the car makes the appropriate, safe response to the data provided

Surprisingly, one of the technology companies that has already successfully introduced driverless vehicles is a spin-out comprising a small handful of college students (Varden Labs, 2016). If technology can give us 360 degree imagery moving at high speed in variable lighting conditions, it should certainly be able to provide a detailed picture of a stationary dairy unit, and if that basic technology can be built by 'college kids' it need not be inherently expensive. Driverless technology is most unlikely to find application in Formula One motor racing. That degree of precision would be almost impossible to achieve, but equally, that application is not needed. So, let us examine what is needed for wellbeing management.

The objective is to assist good husbandry, not replace it. The basis of the assistance is to identify which cows amongst very many are most in need of specialist attention on a particular day, and to provide information (and potentially biological samples) that would help to inform the care given to those cows. Do we need 'precision'? If the objective is to use technology on an intermittent basis to categorise individual animals within a herd as either enjoying wellbeing or not, then a significant degree of precision becomes necessary, as does a gold standard for them to fall either side of. As mentioned previously, that gold standard does not exist (FAWC, 2014). What does exist is the assessment that we could have made of that same cow yesterday, the day before, last week and so on, together with knowledge of her physiological state, genetic background and production parameters. What we are looking for is evidence of change, change that places her outside the currently desirable characteristics and therefore categorises her as 'at risk'. We also have the same information for her herdmates, and we have data relating to her environment, so if the same change is evident at the same time in many animals, the risk is something different, not related to our cow of interest but to the herd as a whole. The driverless car is not trying to constantly maintain a precise and defined distance from the kerb, it is aiming to be somewhere in 'safe territory'. The skilled herdsman with years of experience cannot necessarily say that a particular cow has specific problem $x$, but they can know that there is something not right that requires further intention; they can place her inside or outside 'safe territory'.
The deliverable must be as simple as possible. Farmers are most unlikely to use 'systems' that require them to cross reference between several different pieces of information coming from different sources, and if they did decide to do so, they would be at high risk of not making the correct decision or not being able to make a decision at all. Long before driverless cars, traffic lights provided straightforward information that made a driver's decision easy. Exactly the same needs to be delivered by our wellbeing technology; the green cows in the main group are needing routine management, the amber cows are ones that the technologies are now paying special attention to and the red cows in the holding pen are the ones that the farmer and their vet need to look at now.

Who will deliver this assistance, and to whom? It is evident from Table 1 that there is no shortage of potentially useful technologies, but what is lacking is the skilled herdsman who reduces the information to a simple answer for themself or their boss (one can be reasonably sure that it will often be a 'boss', i.e. the manager of a large unit of some sort). Most probably in future business models the technology will be 'owned' by service providers who will be contracted to place it on farm, receive data from it, interrogate, integrate and analyse that data and then respond with the traffic light message, or simply an automatic move of shedding gates from one position to another. Who will be the customers? 'Big farms' is far too simplistic an answer, for some of the big farms of the future might slowly become big by accident rather than specific design, whereas others might be planned big from the bottom up. The wellbeing monitoring system might have rather different requirements, almost 'rescue' based in the first instance but cost-benefit proven in the second. The third and arguably most important 'big farm' would not be a single farm at all, but a cluster of smaller farms that gather together to dilute investment and overhead costs and then share data in order to maximise the impact of the technology. There are other players too: the immediate response will necessarily involve veterinary professionals, either employed or contracted by the farm or the service provider. Medium term responses will involve dairy consultants, feed advisers and breeding companies, and in the longer term the service provider will share data with national breeding programmes to maximise genetic progress towards improved wellbeing traits.

How will the data integration be achieved? The proprietary problems associated with combining multiple datastreams are already reduced in the business model, nevertheless, integrating numerous datasets is always challenging. In all probability, major strands of future research will include:

- Establishment of minimum effective datasets

- Creation of multiple-output sensors

- Exploitation of multiple endpoints from single datasets

A possible but nevertheless highly speculative model is shown in Fig. 4. This 'Third Sense' approach envisages a 


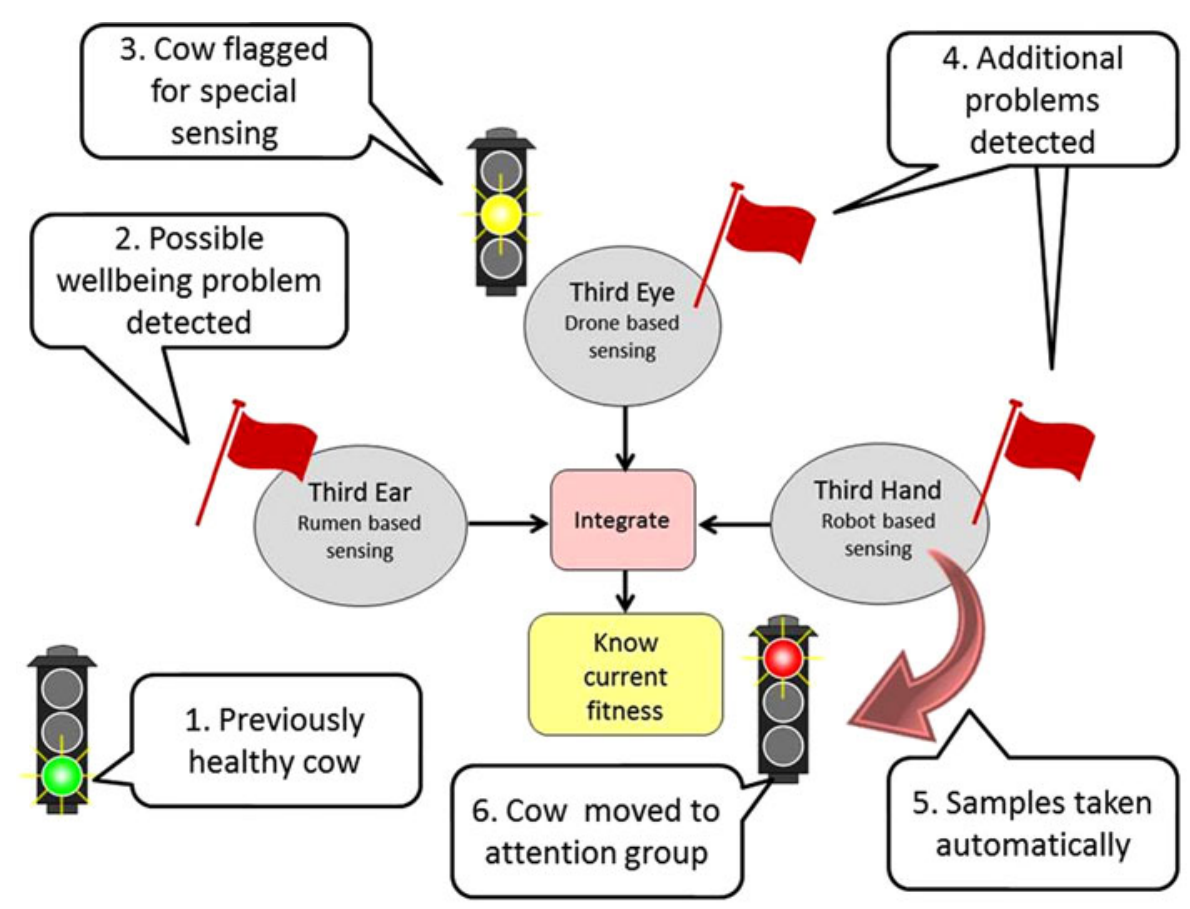

Fig. 4. The Third Sense progressive integration model of wellbeing assessment. This futuristic and speculative model assumes that a multioutput sensor placed in the rumen detects a problem in a previously healthy cow (2). She is flagged for additional monitoring and is followed by a drone that monitors her behaviour (3). Additional problems are detected (4) and on that basis samples of veterinary interest are taken (5) and she is moved to an attention group (6).

multi-output sensor in the rumen (here called the Third Ear, in the sense of inner ear) measuring temperature (which also enables determination of water intake), feed intake, rumen motility, activity, balance, heart rate and $\mathrm{pH}$. Some of these measures already exist (see above), whilst others will need to be developed. Imagine a single 'red flag' raised by the Third Ear in an individual cow that was previously healthy. She is now amber status, and the system deploys the Third Eye and for the next few hours the cow is followed everywhere by a drone that closely monitors her behavioural interactions with other cows and her environment. Sometime later the Third Hand robotic arm reports that a milk sample has returned positive for a metabolic problem and simultaneously the drone reports aberrant behaviour. The cow moves to red status, and next time she leaves the milking unit she is diverted to a holding area for examination. The examining vet will have immediate access to the cow, her data and to samples of, for instance, saliva, interstitial fluid or sweat taken by the Third Hand. This is a 'progressive integration' model which, from an algorithmic point of view, is likely to be relatively simple to model. If numerous red flags have been raised simultaneously the progression would be different; the cow would move immediately to red status and this time the Third Eye would be deployed emitting attractive aromas that she would follow to a holding and sampling area, to ensure that she is seen as rapidly as possible. This model is one of a number that could be proposed; a Third Nose might be monitoring the cow's emissions, for instance. We use the term Third Sense not only to suggest that a small number of sensor streams may be optimal, but also to indicate that it is a third party (us!) who is receiving the information.

Optimistic pipeline, or pie in the sky? Before you decide, remember that Rank Xerox abandoned their own invention, the personal computer, believing it to have no future! The incentive to develop wellbeing technologies for the dairy sector is huge, and could also spawn the development of related technologies for other animal sectors, as well as in human medicine for application in the very young and in elderly dementia sufferers. As a final thought (literally) the drones that were envisaged as a Third Eye can, in theory at least, be controlled by humans simply by thought process (LaFleur et al. 2013). Emotions can be used to fly the drone upwards (happy thoughts) or downwards (sad thoughts). If technology can tap into human thoughts in this way, perhaps knowledge of the cow's mood is actually closer than we might think.

This review is based upon work from COST Action FA1308 DairyCare (DairyCare, 2016), supported by COST (European Cooperation in Science and Technology). COST is a panEuropean intergovernmental framework. Its mission is to enable break-through scientific and technological developments leading to new concepts and products and thereby contributing to strengthening Europe's research and innovation capacities. 


\section{References}

AIC (Association Instituts Carnot) 2010 White paper: Smart Networked Objects \& Internet of Things V 1.0. http://homepages.laas.fr/mkilliji/ docs/books/blanc-carnot.pdf

Albrechtsen M, Duse AT, Bennedsgaard TW \& Klaas IC 2011 Use of in-line measurements of somatic cell count to evaluate treatment efficacy of subclinical bovine Staphylococcus aureus mastitis. In Udder Health and Communication, pp. 309-315 (Ed. H Hogeveen \& TJGM Lam). Wageningen, NL: Wageningen Academic Pub

Berckmans D 2008 Precision livestock farming (PLF). Computers and Electronics in Agriculture $\mathbf{6 2} 1$

Bikker JP, van Laar H, Rump P, Doorenbos J, van Meurs K, Griffioen GM \& Dijkstra J 2014 Evaluation of an ear-attached movement sensor to record cow feeding behavior and activity. Journal of Dairy Science 972974 2979

Bocquier F, Debus N, Lurette A, Maton C, Viudes G, Moulin CH \& Jouven M 2014 Elevage de précision en systèmes d'élevage peu intensifiés. INRA Productions Animales 27 101-112

Caja G, Carné S, Salama AAK, Ait-Saidi A, Rojas-Olivares MA, Rovai M, Capote J, Castro N, Argüello A, Ayadi M, Aljumaah R \& Alshaikh MA 2014 State-of-the-art of electronic identification techniques and applications in goats. Small Ruminant Research 121 42-50

Capper JL, Cady RA \& Bauman DE 2009 The environmental impact of dairy production: 1944 compared with 2007. Journal of Animal Science 87 2160-2167

Castro-Costa A, Caja G, Salama AAK, Rovai M, Flores C \& Aguiló J 2014 Thermographic variation of the udder of dairy ewes at early-lactation and following an E. coli endotoxin intramammary Chalena at late-lactation. Journal of Dairy Science $\mathbf{9 7} 1377-1387$

Chiumia D, Chagunda MGG, Macrae Al \& Roberts DJ 2013 Predisposing factors for involuntary culling in Holstein-Friesian dairy cows. Journal of Dairy Research $\mathbf{8 0} 45-50$

DairyCare 2016 European Commission COST Action FA1308 http://www. dairycareaction.org/

De Marchi M, Toffanin V, Cassandro M \& Penasa M 2014 Mid-infrared spectroscopy as phenotyping tool for milk traits. Journal of Dairy Science 97 1171-1186

De Vries M, Bokkers EA, van Schaik G, Botreau R, Engel B, Dijkstra T \& de Boer IJ 2013 Evaluating results of the Welfare Quality multi-criteria evaluation model for classification of dairy cattle welfare at the herd level. Journal of Dairy Science 96 6264-6273

Duncan IJH \& Fraser D 1997 Understanding animal welfare. In Animal Welfare, pp. 19-31 (Ed. MA Appleby \& BO Hughes). Wallingford, UK: CABI Publishers

EU-PLF 2016 Smart farming for Europe http://www.eu-plf.eu/

FAOStat 2016. Food and Agricultural Organization of the United Nations, Statistics Division. Livestock Primary. http://faostat3.fao.org/download/ $\mathrm{Q} / \mathrm{QL} / \mathrm{E}$

Farm Animal Welfare Council (FAWC) 2014 FAWC reviews the evidence base for animal welfare. Veterinary Record 17533

Forkman B \& Keeling L 2009 Assessment of animal welfare measures for dairy cattle, beef bulls and veal calves. In Welfare Quality ${ }^{\oplus}$ report 11 Series pp 1-175 (Ed. M Miele \& J Roex). Cardiff, UK: Cardiff University FP7-ProHealth 2016 http://www.fp7-prohealth.eu/

Hadley GL, Wolf CA \& Harsh SB 2006 Dairy cattle culling patterns, explanations, and implications. Journal of Dairy Science 89 2286-2296
Hanton JP \& Leach HA 1974 Electronic livestock identification system. US Patent No. 4262632

Itle AJ, Huzzey JM, Weary DM \& von Keyserlingk MAG 2015 Clinical ketosis and standing behavior in transition cows. Journal of Dairy Science 98 128-134

Krukowski M 2009 Automatic determination of body condition score of dairy cows from 3D images. MSci Thesis. Stockholm, Sweden: Royal Institute of Technology, School of Computer Science and Communication

LaFleur K, Cassady K, Doud A, Shades K, Rogin E \& He B 2013 Quadcopter control in three-dimensional space using a noninvasive motor imagerybased brain-computer interface. Journal of Neural Engineering 10 1-15

Larsen T, Alstrup L \& Weisbjerg MR 2016 Minor milk constituents are affected by protein concentration and forage digestibility in the feed ration. Journal of Dairy Research 83 12-19

Leitner G, Merin U, Lemberskiy-Kuzin L, Bezman D \& Katz G 2012 Realtime visual/near-infrared analysis of milk-clotting parameters for industrial applications. Animal 6 1170-1177

Madouasse A, Huxley JN, Browne WJ, Bradley AJ, Dryden IL \& Green MJ 2010 Use of individual cow milk recording data at the start of lactation to predict the calving to conception interval. Journal of Dairy Science 93 4677-4690

Michaelis I, Burfeind O \& Heuwieser W 2014 Evaluation of oestrous detection in dairy cattle comparing an automated activity monitoring system to visual observation. Reproduction in Domestic Animals 49 621-628

Milán MJ, Caja G, González-González R, Férnández-Pérez AM \& Such X 2011 Structure and performance of Awassi and Assaf dairy sheep farms in northwestern Spain. Journal of Dairy Science 94 771-784

Mohd-Nor NM, Steeneveld W \& Hogeveen H 2014 The average culling rate of Dutch dairy herds over the years 2007 to 2010 and its association with herd reproduction, performance and health. Journal of Dairy Research 81 1-8

Mugera AW \& Bitsch V 2005 Managing labor on dairy farms: a resourcebased perspective with evidence from case studies. International Food and Agribusiness Management Review 8 79-98

Rutten CJ, Velthuis AGJ, Steeneveld W \& Hogeveen H 2013 Sensors to support health management on dairy farms. Journal of Dairy Science 96 1928-1952

smaXtec 2016 http://www.smaxtec-animalcare.com/en/

Spicka J \& Smutka L 2014 The technical efficiency of specialised milk farms: a regional view. The Scientific World Journal 2014 1-13

Sutton JD \& Morant SV 1989 A review of the potential of nutrition to modify milk fat and protein. Livestock Production Science 23 219-237

van Gastelen S \& Dijkstra J 2016 Prediction of methane emission from lactating dairy cows using milk fatty acids and mid-infrared spectroscopy. Journal of the Science of Food and Agriculture 96 http://onlinelibrary. wiley.com/doi/10.1002/jsfa.7718/pdf

Varden Labs 2016 http://vardenlabs.com/

Walsh RB, Walton JS, Kelton DF, LeBlanc SJ, Leslie KE \& Duffield TF 2007 The effect of subclinical ketosis in early lactation on reproductive performance of postpartum dairy cows. Journal of Dairy Science $\mathbf{9 0} 2788-$ 2796

WHO 1946 Constitution of the World Health Organisation. American Journal of Public Health and Nations Health 36 1315-1323

Zobel G, Leslie K, Weary DM \& von Keyserlingk MAG 2015 Ketonemia in dairy goats: effect of dry period length and effect on lying behavior. Journal of Dairy Science $\mathbf{9 8}$ 6128-6138 